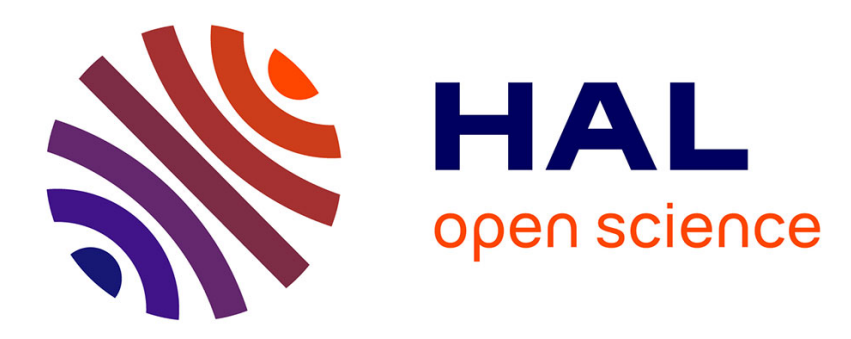

\title{
Differential theory of diffraction in cylindrical coordinates
}

E. Popov, N. Bonod

\section{To cite this version:}

E. Popov, N. Bonod. Differential theory of diffraction in cylindrical coordinates. physica status solidi (b), 2007, 244 (10), pp.3463-3478. hal-00223025

\section{HAL Id: hal-00223025 \\ https://hal.science/hal-00223025}

Submitted on 30 Jan 2008

HAL is a multi-disciplinary open access archive for the deposit and dissemination of scientific research documents, whether they are published or not. The documents may come from teaching and research institutions in France or abroad, or from public or private research centers.
L'archive ouverte pluridisciplinaire $\mathbf{H A L}$, est destinée au dépôt et à la diffusion de documents scientifiques de niveau recherche, publiés ou non, émanant des établissements d'enseignement et de recherche français ou étrangers, des laboratoires publics ou privés. 


\title{
Differential theory of diffraction in cylindrical coordinates
}

\author{
E. Popov and N. Bonod \\ Institut Fresnel, CNRS, UMR6163, Aix-Marseille Université, Fac. St. Jérôme, Ave. Escadrille Normandie- \\ Niemen, 13397 Marseille Cedex 20, France
}

\begin{abstract}
The principles of the differential theory of light diffraction are presented in cylindrical coordinates. Special attention is played to the factorisation rules necessary to obtain faster convergence with respect to the number of basic functions used in the field representation. A detailed description is given for diffracting objects having rotational symmetry and finite cylindrical length. Some properties of light diffracted by a single circular aperture piereced in a finitely conducting screen are discussed, including the excitation of surface plasmon wave and the enhanced beaming.
\end{abstract}

\section{Introduction}

The differential theory of light diffraction [1-3] is based on the integration of a differential set of equations derived from the Maxwell equations, projected on some functional bases, a projection used to reduce the problem from 3-dimensional integration to a set of ordinary differential equations. The basic idea is to use one and the same basis in different media constituting the diffraction system, in contrast with the so-called proper modal methods, which use different basis adapted to each medium [4], which leads to numerical problems in solving the corresponding characteristic equations [5].

First attempts to implement numerically the differential method were made in the early '70s [6, 7]. They were based on numerical integration of a second-order differential set, in analogy with a similar problem coming from the Schrödinger equation [8]. However, the vectorial character of the electromagnetic field made it more natural the use of first-order differential set obtained directly from the Maxwell equations, especially in TM polarization with electric field vector perpendicular to the grating grooves $[9,10]$.

An alternative method was developed to avoid numerical integration, quite suitable for lamellar gratings and based on eigenvalues/eigenvectors technique (as discussed in Sec.5). Following the works of Moharam and Gaylord [11. 12] the method is called 'rigorous coupled-wave (RCW) theory,' despite the ambiguity of the name. Earlier works by Peng [13] and Krupitsky and Chernov [14] propose similar formulations, but are less known to the scientific community.

Fig. 1 Schematical representation of a crossed grating

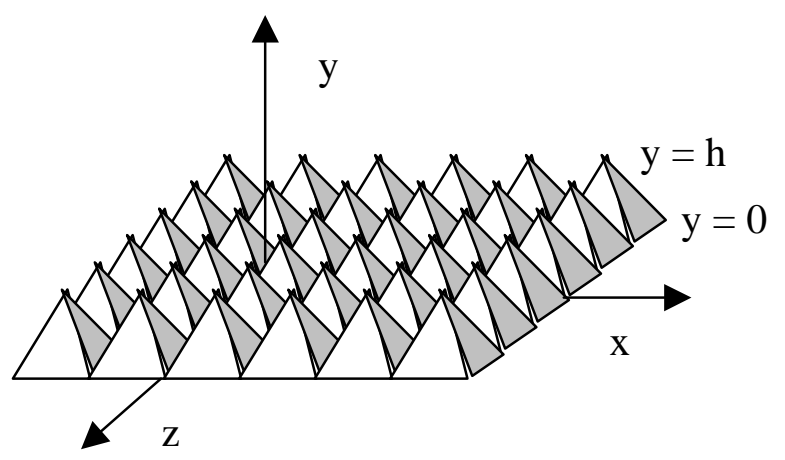

The aim of this paper is to present the general principles of the differential method, the difficulties that appear in its earlier formulations, together with the recent advances in overcoming them (Sec.2 and 3). A detailed study is proposed in cylindrical coordinates (Sec.4 - 7), in view of the recent theoretical and practical interest devoted to diffraction by single or periodical apertures in physics, biology and chemistry.

The basic idea of the differential method can be more easily understood in Cartesian coordinates. Systems having one-, two-, or three-dimensional periodicity (classical, multilayered, or crossed gratings, photonic crystals, hole arrays) are naturally modelled in Cartesian coordinates having orthogonal or nonorthogonal basis, depending on the form of the elementary cell. For example, a crossed grating with rectangular cell, periodic in $\mathrm{x}$ and z-directions (Fig.1) can be treated in a basis of exponential functions:

$$
\exp \left[i\left(k_{x, m} x+k_{z, p} z\right)\right], \quad m, p \text { - integers }
$$


where $\mathrm{k}_{\mathrm{x}, \mathrm{m}}=\mathrm{k}_{\mathrm{x}, 0}+\mathrm{mK}_{\mathrm{x}}$ and $\mathrm{k}_{\mathrm{z}, \mathrm{p}}=\mathrm{k}_{\mathrm{z}, 0}+\mathrm{pK}_{\mathrm{z}}$ are the $\mathrm{x}$ and $\mathrm{z}$ wavenumbers of the diffraction orders, determined from the incident wavenumbers $\left(\mathrm{k}_{\mathrm{x}, 0}, \mathrm{k}_{\mathrm{z}, 0}\right)$ and the periods $\mathrm{d}_{\mathrm{x}}$ and $\mathrm{d}_{\mathrm{y}}$ in $\mathrm{x}$ and $\mathrm{z}$ direction $\left(\mathrm{K}_{\mathrm{x}}=2 \pi / \mathrm{d}_{\mathrm{x}}, \mathrm{K}_{\mathrm{z}}=2 \pi / \mathrm{d}_{\mathrm{z}}\right)$.

The electromagnetic field components can be represented in the basis (1) in the form of unknown amplitudes, which depend only on y-coordinate. For example, the x-component of the electric field vector is given in the form:

$$
\mathrm{E}_{\mathrm{x}}(\mathrm{x}, \mathrm{y}, \mathrm{z})=\sum_{\mathrm{m}, \mathrm{p}=-\infty}^{\infty} \mathrm{E}_{\mathrm{x}, \mathrm{m}, \mathrm{p}}(\mathrm{y}) \exp \left[\mathrm{i}\left(\mathrm{k}_{\mathrm{x}, \mathrm{m}} \mathrm{x}+\mathrm{k}_{\mathrm{z}, \mathrm{p}} \mathrm{z}\right)\right]
$$

In the substrate and the cladding outside the grating region, which extends from $\mathrm{y}=0$ to $\mathrm{y}=\mathrm{h}$ (Fig.1), the form of the field amplitude $E_{x, m, p}$ is determined by the wave equation in a homogeneous medium:

$$
\mathrm{E}_{\mathrm{x}, \mathrm{m}, \mathrm{p}}(\mathrm{y})=\mathrm{A}_{\mathrm{x}, \mathrm{m}, \mathrm{p}}^{ \pm} \exp \left( \pm \mathrm{ik}_{\mathrm{y}, \mathrm{m}, \mathrm{p}} \mathrm{y}\right)
$$

with $\mathrm{k}_{\mathrm{y}, \mathrm{m}, \mathrm{p}}=\sqrt{\mathrm{k}^{2}-\mathrm{k}_{\mathrm{x}, \mathrm{m}}^{2}-\mathrm{k}_{\mathrm{z}, \mathrm{p}}^{2}}$ and $\mathrm{k}$ is the wavenumber in the corresponding medium. Inside the grating region $(0 \leq y \leq h)$, the field cannot be represented as a sum of plane waves and it is necessary to solve numerically the set of differential equations for $E_{x, m, p}$, as well as for the other field vector components. The entire history of the differential theory and its numerical implementation is devoted to this problem, which consists of several tasks: formulation of the differential set, numerical integration of the set, and application of the boundary conditions at $\mathrm{y}=0, \mathrm{~h}$.

\section{S-matrix propagation algorithm}

There were two major difficulties in obtaining an operational method. The first one is due to the fact that when a system of differential equation is integrated along some propagation distance, numerical instabilities grow exponentially with this distance and lead to ill-conditioned system. A simple but typical example enables us to understand the origin of the difficulty and indicates a possibility of its elimination. Let us consider a homogeneous layer extending from $x=x_{0}$ to $x=x_{1}$. If we try to propagate a single plane wave from point $\mathrm{M}_{0}\left(\mathrm{x}_{0}\right)$ to point $\mathrm{M}_{1}\left(\mathrm{x}_{1}\right)$, it is necessary to consider two waves propagating in opposite directions:

$$
\begin{aligned}
& E_{y}^{+}=A^{+} \exp (i k x) \\
& E_{y}^{-}=A^{-} \exp (-i k x)
\end{aligned}
$$

and the link between the field at $\mathrm{x}_{0}$ and $\mathrm{x}_{1}$ is given by the so-called transmission matrix $\mathrm{T}$ of the layer:

$$
\left(\begin{array}{l}
E_{y}^{+}\left(x_{1}\right) \\
E_{y}^{-}\left(x_{1}\right)
\end{array}\right)=T\left(\begin{array}{l}
E_{y}^{+}\left(x_{0}\right) \\
E_{y}^{-}\left(x_{0}\right)
\end{array}\right)=\left(\begin{array}{cc}
\exp \left[i k\left(x_{1}-x_{0}\right)\right] & 0 \\
0 & \exp \left[-i k\left(x_{1}-x_{0}\right)\right]
\end{array}\right)\left(\begin{array}{l}
E_{y}^{+}\left(x_{0}\right) \\
E_{y}^{-}\left(x_{0}\right)
\end{array}\right)
$$

If it is necessary to take into account the evanescent waves with $\operatorname{Im}(k)>0$, the exponential term of T22 having negative sign diverges when $\mathrm{x}_{1}-\mathrm{x}_{0}$ becomes sufficiently large. This can be avoided by suitable renormalization in the case of plane wave expansion, but this is impossible when the explicit form of the field is unknown, as it happens in case of inhomogeneous media. During the '90s, this problem was definitely solved in electromagnetism by applying [15] a propagation algorithm (called S-matrix algorithm) already known in other domains of science [16, 17]. It is easy to understand the idea by slightly changing eq.(5):

$$
\left(\begin{array}{l}
E_{y}^{+}\left(x_{1}\right) \\
E_{y}^{-}\left(x_{0}\right)
\end{array}\right)=S\left(\begin{array}{c}
E_{y}^{+}\left(x_{0}\right) \\
E_{y}^{-}\left(x_{1}\right)
\end{array}\right)=\left(\begin{array}{cc}
\exp \left[i k\left(x_{1}-x_{0}\right)\right] & 0 \\
0 & \exp \left[i k\left(x_{1}-x_{0}\right)\right]
\end{array}\right)\left(\begin{array}{l}
E_{y}^{+}\left(x_{0}\right) \\
E_{y}^{-}\left(x_{1}\right)
\end{array}\right)
$$

so that the new matrix $S$ represents the scattering matrix of the system that links the field incident on the structure $\left(\mathrm{E}_{\mathrm{y}}^{+}\right.$at $\mathrm{x}_{0}$ and $\mathrm{E}_{\mathrm{y}}^{-}$at $\mathrm{x}_{1}$ ) to the field scattered by the system $\left(\mathrm{E}_{\mathrm{y}}^{+}\right.$at $\mathrm{x}_{1}$ and $\mathrm{E}_{\mathrm{y}}^{-}$at $\mathrm{x}_{0}$ ), by taking into account that the + components propagates towards $+x$ and the - components travels along $-x$, assuming $\exp (-$ i $\omega t)$ time dependence. As can be observed, even for evanescent field whatever the propagation distance, the Smatrix doe not diverge. However, special attention must be made in correctly treating underflows. 
However, this evident solution is not so simple to apply in practice for an inhomogeneous system, where the forward and backward propagating amplitude are coupled inside the structure, because field is determined by propagating it from one point to another, i.e., numerical (or analytical, when possible) integration gives naturally the T-matrix. To solve this difficulty, it is necessary to divide the inhomogeneous domain into subdomains (slices), small enough so that it is possible to determine the $\mathrm{T}^{(\mathrm{j})}$-matrix for each slice (numbered $\mathrm{j}$ ) without numerical instability. A simple recurrence formula [15] enables then to determine the $S^{(j)}$-matrix for each set of slices starting from the first one $(j=1)$ of the set:

$$
\begin{aligned}
& Z^{(j)}=\left(T_{11}^{(j)}+T_{12}^{(j)} S_{12}^{(j-1)}\right)^{-1} \\
& S_{22}^{(j)}=S_{22}^{(j-1)} Z^{(j)} \\
& S_{12}^{(j)}=\left(T_{21}^{(j)}+T_{22}^{(j)} S_{12}^{(j-1)}\right) Z^{(j)} \\
& S_{21}^{(j)}=S_{21}^{(j-1)}-S_{22}^{(j)} T_{12}^{(j)} S_{11}^{(j-1)} \\
& S_{11}^{(j)}=-S_{12}^{(j)} T_{12}^{(j)} S_{11}^{(j-1)}+T_{22}^{(j)} S_{11}^{(j-1)}
\end{aligned}
$$

The initial (zero-slice) S-matrix is equal to the unity matrix. It has to be taken into account that contrary to eqs.(5) and (6), in case of inhomogeneous media the elements of the $S$ and the T-matrices represent block matrices.

\section{The factorization rules}

The second major problem that restricted for quite a long time the applications of the differential method to only dielectric or shallow metallic gratings came from the necessity to truncate the otherwise infinite series in eq.(2), inevitable in numerical modelling of the diffraction problem. It is well known that the convergence of the Fourier representation of a given function with respect to the truncation parameter $\mathrm{N}$ (with $2 \mathrm{~N}+1$ being the number of Fourier components retained in the representation) depends strongly on the type of the function. If the function is continuous, the convergence is, in general, of the order of $\mathrm{N}^{-2}$, while discontinuous functions converge not faster than $\mathrm{N}^{-1}$. Unfortunately, electromagnetism deals with both continuous and discontinuous functions. In the case of non-magnetic materials (as studied everywhere in this paper), magnetic field and induction are continuous functions of the space variables. However, given an object with different electric permittivity, electric field normal components $E_{N}$ and electric induction tangential components $D_{T}$ are discontinuous across its surfaces, and they all participate in the Maxwell equations.

Let us at first consider a simple case of a sinusoidal aluminium grating illuminated in TE or TM polarization (electric field vector parallel or perpendicular to the grooves) [2]. When the groove depth-to-period ratio is $40 \%$, corresponding to the mostly used commercial gratings, the convergence in TE polarization is rapidly reached and precision to within $0.5 \%$ is easily obtained for $\mathrm{N}>6$. However, in $\mathrm{TM}$ polarization it is not sufficient to go up to 300 Fourier components $(\mathrm{N}=150)$ to reach satisfactory results (Fig.2). While in the case of classical gratings it is possible to further increase $\mathrm{N}$ (to, say, $\mathrm{N}=1000$ ), crossed gratings and 3-dimensional photonic crystals cannot be treated numerically by retaining such great number of field components, because this requires solving a system of $[4(2 \mathrm{~N}+1)]^{2}$ differential equations. The improvement of the method is spectacular, when using the correct factorization rules, described later in the paper.

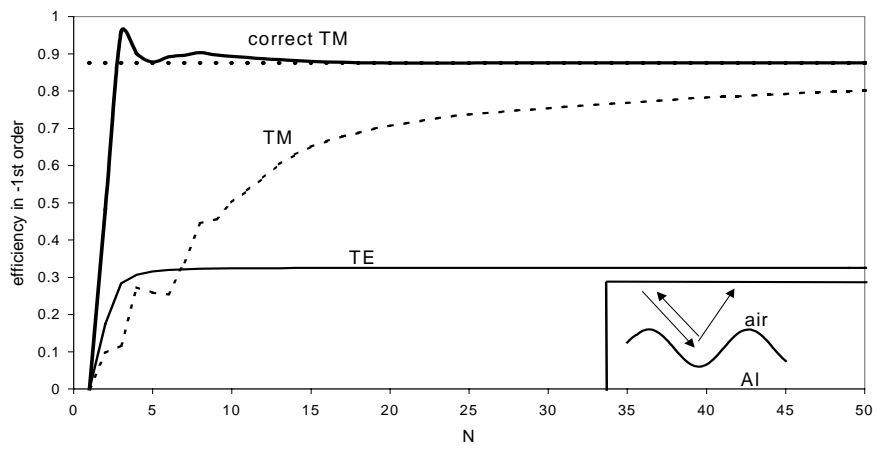

Fig. 2 Convergence of the $-1^{\text {st }}$ order diffraction efficiency of an aluminium grating used in Littrow mount at $\lambda=$ $0.6328 \mu \mathrm{m}$. Period is $\mathrm{d}=0.5 \mu \mathrm{m}$ and groove depth is $\mathrm{h}=0.2 \mu \mathrm{m}$, refractive index $\mathrm{n}=1.3+\mathrm{i}$ 7.6. Curve 'TM' classical differential method, curve labelled as 'correct TM' - improved method [2]. 
The origin of the difference between the convergence rates of TE and TM polarization has been explained since long time by the fact that in TE polarization the only nonzero component of the electric field vector is tangential to the groove surface and thus continuous. However, this explanation was not sufficient to provide a solution, at least till the works of Lalanne at el. [18] and Granet and Guizal [19] that proposed a fast convergence formulation for lamellar gratings, discussed later. The theoretical explanation of this fast convergence was made by Li $[20,21]$ who challenged the validity of the well-known convolution rule of presenting the product of functions in a truncated Fourier basis. While the convolution rule is rigorously valid for an infinite series representation, computer implementation of a theory requires truncation of the basis, and in this truncated basis it is possible, in some cases, to formulate a new rule, which is more rapidly converging with the truncation number.

Recent studies have extended the use of the Li's truncation rules to other methods [22]. One can find in ref.[23] a detailed presentation of the conventional convolution rule and the rules proposed by Li, extended to any orthonormal basis of continuous functions. The basic idea can be easily understood on a single example of an extreme truncation of the series, where only a single term is retained [18, 23]. In an one-dimensional Fourier basis this means simply to calculate the mean value of the product of two functions $h(x)=f(x) g(x)$ as a function of the mean values of $f(x)$ and $g(x)$.. At first, let us consider that function $g(x)$ is constant. Then the mean value of $h$ is the product of the mean values of $g$ and of $f$ :

$$
\mathrm{g}=\text { const. } \Rightarrow \overline{\mathrm{h}}=\overline{\mathrm{f}} \overline{\mathrm{g}}
$$

Second, let us consider two piecewise constant functions:

$$
f(x)=\left\{\begin{array}{ll}
a, & x<0 \\
b, & x<0
\end{array}, \quad g(x)=\left\{\begin{array}{ll}
b, & x<0 \\
a, & x<0
\end{array}, \quad h(x)=a b\right.\right.
$$

so that their mean values is simply given as:

$$
\overline{\mathrm{f}}=\overline{\mathrm{g}}=(\mathrm{a}+\mathrm{b}) / 2, \quad \overline{\mathrm{h}}=\mathrm{ab} \neq\langle\mathrm{f}\rangle\langle\mathrm{g}\rangle=(\mathrm{a}+\mathrm{b})^{2} / 4
$$

and thus, in general, the mean value of $\mathrm{h}=\mathrm{fg}$ is not given as the product of the mean values of $\mathrm{f}$ and g. However, if we consider the product of $1 / \mathrm{f}$ and $\mathrm{h}$, as $\mathrm{h}=$ const. we can apply eq.(8):

$$
\overline{\mathrm{g}}=\overline{\left(\frac{1}{\mathrm{f}}\right)} \overline{\mathrm{h}} \Leftrightarrow \frac{\mathrm{a}+\mathrm{b}}{2}=\left(\frac{1}{2 \mathrm{a}}+\frac{1}{2 \mathrm{~b}}\right) \mathrm{ab}
$$

and thus another rule can be obtained:

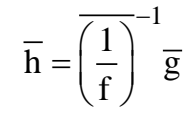

called by Li the inverse rule, in opposition to eq. (8), called the direct rule. Whatever the basis of functions used [23], these rules has to be used in order to obtain faster convergence with respect to the truncated number of basic functions used in the numerical implementation of the differential method. They can be formulated in the following general form:

Given an infinite basis of continuous functions $\left\{\varphi_{\mathrm{m}}\right\}$ forming a linear space, the decomposition $[\mathrm{h}]$ of a product $\mathrm{h}$ of two arbitrary functions $\mathrm{f}$ and $\mathrm{g}$ in this basis can be represented as a combination of the decompositions [f] and [g] of the two functions in the same basis. If the two functions don't have points of simultaneous discontinuity, a rule corresponding to the Laurent's rule for Fourier basis applies, called direct rule:

$$
[\mathrm{h}]_{\mathrm{m}}=\sum_{\mathrm{p}} \llbracket \mathrm{f} \rrbracket_{\mathrm{mp}}[\mathrm{g}]_{\mathrm{p}}
$$

where

$$
\left.[\mathrm{h}]_{\mathrm{m}}=|\mathrm{h}| \varphi_{\mathrm{m}}\right\rangle
$$

is the projection of $\mathrm{h}$ on the $\mathrm{m}$-th base function, and

$$
\llbracket \mathrm{f} \rrbracket_{\mathrm{mp}}=\left\langle\varphi_{\mathrm{m}}|\mathrm{f}| \varphi_{\mathrm{p}}\right\rangle
$$


represents the matrix element of $f$ over the direct and the adjoint basis. The angular brackets stay for the scalar product defined in the corresponding basis. For example, in a 1-D Fourier basis applied to periodic functions with period d, we have:

$$
\begin{aligned}
& \varphi_{\mathrm{m}}(\mathrm{x})=\exp (\mathrm{imKx}), \quad \mathrm{K}=2 \pi / \mathrm{d} \\
& \left.|\mathrm{f}(\mathrm{x})| \varphi_{\mathrm{m}}(\mathrm{x})\right\rangle=\frac{1}{\mathrm{~d}} \int_{0}^{\mathrm{d}} \mathrm{f}(\mathrm{x}) \exp (\mathrm{imKx}) \mathrm{dx} \\
& \left\langle\varphi_{\mathrm{m}}(\mathrm{x})|\mathrm{f}(\mathrm{x})| \varphi_{\mathrm{p}}(\mathrm{x})\right\rangle=\frac{1}{\mathrm{~d}} \int_{0}^{\mathrm{d}} \mathrm{f}(\mathrm{x}) \exp [\mathrm{i}(\mathrm{m}-\mathrm{n}) \mathrm{Kx}] \mathrm{dx}
\end{aligned}
$$

If the index of the base functions is a continuous variable (for example, aperiodic functions), then the sum in eq.(13) is replaced by an integral.

The second case concerns the product of functions having points of simultaneous reciprocal discontinuities, so that their product is continuous in these points. An inverse rule, more rapidly convergent than eq., can be formulated, similar to eq.(12):

$$
[\mathrm{h}]_{\mathrm{m}}=\sum_{\mathrm{p}} \llbracket \mathrm{f}_{\mathrm{inv}} \rrbracket_{\mathrm{mp}}[\mathrm{g}]_{\mathrm{p}}
$$

where $\llbracket \mathrm{f}_{\mathrm{inv}} \rrbracket_{\mathrm{mp}}$ represents the m,p element of the inverted square matrix $\llbracket \mathrm{f}_{\text {inv }} \rrbracket$ made of the elements of the projection of $1 / \mathrm{f}$ :

$$
\llbracket \mathrm{f}_{\text {inv }} \rrbracket=\llbracket \frac{1}{\mathrm{f}} \rrbracket^{-1}=\left(\left\{\left\langle\varphi_{\mathrm{m}}\left|\frac{1}{\mathrm{f}}\right| \varphi_{\mathrm{p}}\right\rangle\right\}\right)^{-1}
$$

In the most general situation when the three functions $\mathrm{h}, \mathrm{f}$, and $\mathrm{g}$ have points of simultaneous discontinuity, neither the direct nor the inverse rule give satisfactory convergence rate, but it is often possible to find a suitable combination of the two rules.

These rules are of great importance in electromagnetism, because there are two products that participate in the Maxwell equations, namely the electric field vector $\vec{E}$ multiplied by the electric permittivity tensor $\varepsilon$, and the magnetic field vector $\overrightarrow{\mathrm{H}}$ multiplied by the magnetic permeability tensor $\mu$. Let us consider linear, local, instantaneous, and non-magnetic response, and concentrate on the electric induction:

$$
\overrightarrow{\mathrm{D}}=\varepsilon \overrightarrow{\mathrm{E}}
$$

The case of magnetic media can be treated in a similar manner. The non-linear response can also be modelled, as shown in ref. [24].

The three functions $\vec{D}, \varepsilon$, and $\vec{E}$ are simultaneously discontinuous on the surface of a physical object. However, it is possible to separate $\vec{D}$ in two parts, each one corresponding to the first or the second case discussed above. The normal part of $\vec{D}$ is continuous across the surface of the object and thus the discontinuities of $\varepsilon$ and $\overrightarrow{\mathrm{E}}$ are reciprocal, thus the inverse rule applies:

$$
\left[\overrightarrow{\mathrm{D}}_{\mathrm{N}}\right]=\llbracket \frac{1}{\varepsilon} \rrbracket^{-1}\left[\overrightarrow{\mathrm{E}}_{\mathrm{N}}\right]
$$

The remaining (tangential) part of $\overrightarrow{\mathrm{D}}$ can be treated according to the direct rule, because the tangential part of $\overrightarrow{\mathrm{E}}$ is continuous across any surface

Thus,

$$
\left[\overrightarrow{\mathrm{D}}_{\mathrm{T}}\right]=\llbracket \varepsilon \rrbracket\left[\overrightarrow{\mathrm{E}}_{\mathrm{T}}\right]
$$

$$
[\overrightarrow{\mathrm{D}}]=\left[\overrightarrow{\mathrm{D}}_{\mathrm{N}}\right]+\left[\overrightarrow{\mathrm{D}}_{\mathrm{T}}\right]=\llbracket \frac{1}{\varepsilon} \rrbracket^{-1}\left[\overrightarrow{\mathrm{E}}_{\mathrm{N}}\right]+\llbracket \varepsilon \rrbracket\left[\overrightarrow{\mathrm{E}}_{\mathrm{T}}\right]
$$

The relations:

can be used to simplify eq.(22):

$$
\begin{aligned}
& \overrightarrow{\mathrm{E}}_{\mathrm{N}}=\overrightarrow{\mathrm{N}}(\overrightarrow{\mathrm{N}} \cdot \overrightarrow{\mathrm{E}}) \\
& \overrightarrow{\mathrm{E}}_{\mathrm{T}}=\overrightarrow{\mathrm{E}}-\overrightarrow{\mathrm{E}}_{\mathrm{N}}
\end{aligned}
$$

$$
[\overrightarrow{\mathrm{D}}]=(\llbracket \varepsilon \rrbracket-\Delta \llbracket \overrightarrow{\mathrm{N}} \overrightarrow{\mathrm{N}} \rrbracket)[\overrightarrow{\mathrm{E}}]
$$

with the matrix $\Delta$ : 


$$
\Delta=\llbracket \varepsilon \rrbracket-\llbracket \frac{1}{\varepsilon} \rrbracket^{-1}
$$

vanishing without truncating the number of basic functions, and eq.(24) simplifies to eq.(13). However, it becomes significantly different from zero in case of truncation and its use contributes to a significant acceleration of the convergence rate with respect to the basis truncation. In the anisotropic case, a special attention is required because $\vec{D}$ and $\vec{E}$ are non-parallel, in general [2].

\section{The differential equations in cylindrical coordinates}

Let us consider a cylindrical coordinate system $(r, \theta, z)$, as presented schematically in Fig.3. Using Fourier representation on the basis $\exp (\operatorname{in} \theta)$, Maxwell equations for the $\mathrm{r}-, \theta$-, and $\mathrm{z}$ - components of electric and magnetic field $E_{r}, E_{\theta}, E_{z}, H_{r}, H_{\theta}$, and $H_{z}$ can be written in the following form:

$$
\begin{aligned}
& \frac{\partial \mathrm{E}_{\theta, \mathrm{n}}}{\partial \mathrm{z}}=\frac{\mathrm{in}}{\mathrm{r}} \mathrm{E}_{\mathrm{z}, \mathrm{n}}-\mathrm{i} \omega \mu_{0} \mathrm{H}_{\mathrm{r}, \mathrm{n}} \\
& \frac{\partial \mathrm{E}_{\mathrm{r}, \mathrm{n}}}{\partial \mathrm{z}}=\frac{\partial \mathrm{E}_{\mathrm{z}, \mathrm{n}}}{\partial \mathrm{r}}+\mathrm{i} \omega \mu_{0} \mathrm{H}_{\theta, \mathrm{n}} \\
& \mathrm{i} \omega \mu_{0} \mathrm{H}_{\mathrm{z}, \mathrm{n}}=\frac{\partial \mathrm{E}_{\theta, \mathrm{n}}}{\partial \mathrm{r}}+\frac{\mathrm{E}_{\theta, \mathrm{n}}}{\mathrm{r}}-\frac{\mathrm{in}}{\mathrm{r}} \mathrm{E}_{\mathrm{r}, \mathrm{n}} \\
& \frac{\partial \mathrm{H}_{\theta, \mathrm{n}}}{\partial \mathrm{z}}=\frac{\mathrm{in}}{\mathrm{r}} \mathrm{H}_{\mathrm{z}, \mathrm{n}}+i \omega \mathrm{D}_{\mathrm{r}, \mathrm{n}} \\
& \frac{\partial \mathrm{H}_{\mathrm{r}, \mathrm{n}}}{\partial \mathrm{z}}=\frac{\partial \mathrm{H}_{\mathrm{z,n}}}{\partial \mathrm{r}}-\mathrm{i} \omega \mathrm{D}_{\theta, \mathrm{n}} \\
& -\mathrm{i} \omega \mathrm{D}_{\mathrm{z}, \mathrm{n}}=\frac{\partial \mathrm{H}_{\theta, \mathrm{n}}}{\partial \mathrm{r}}+\frac{\mathrm{H}_{\theta, \mathrm{n}}}{\mathrm{r}}-\frac{i \mathrm{n}}{\mathrm{r}} \mathrm{H}_{\mathrm{r}, \mathrm{n}}
\end{aligned}
$$

The propagation equations are then coupled:

Using the notations:

$$
\begin{aligned}
& \Delta \mathrm{E}_{\mathrm{r}, \mathrm{n}}-\frac{\mathrm{E}_{\mathrm{r}, \mathrm{n}}}{\mathrm{r}^{2}}+\omega^{2} \mu_{0} \varepsilon(\mathrm{r}) \mathrm{E}_{\mathrm{r}, \mathrm{n}}-\frac{2 \mathrm{in}}{\mathrm{r}^{2}} \mathrm{E}_{\theta, \mathrm{n}}=0 \\
& \Delta \mathrm{E}_{\theta, \mathrm{n}}-\frac{\mathrm{E}_{\theta, \mathrm{n}}}{\mathrm{r}^{2}}+\omega^{2} \mu_{0} \varepsilon(\mathrm{r}) \mathrm{E}_{\theta, \mathrm{n}}+\frac{2 \mathrm{in}}{\mathrm{r}^{2}} \mathrm{E}_{\mathrm{r}, \mathrm{n}}=0
\end{aligned}
$$

$$
\begin{aligned}
& E_{\theta, \mathrm{n}}+\mathrm{iE}_{\mathrm{r}, \mathrm{n}}=\mathrm{E}_{\mathrm{n}}^{+} \\
& \mathrm{E}_{\theta, \mathrm{n}}-\mathrm{iE}_{\mathrm{r}, \mathrm{n}}=\mathrm{E}_{\mathrm{n}}^{-}
\end{aligned}
$$

eqs.(27) and (28) can be decoupled:

$$
\begin{aligned}
& \Delta E_{n}^{+}-\frac{E_{n}^{+}}{r^{2}}+\omega^{2} \mu_{0} \varepsilon(r) E_{n}^{+}+\frac{2 n}{r^{2}} E_{n}^{+}=0 \\
& \Delta E_{n}^{-}-\frac{E_{n}^{-}}{r^{2}}+\omega^{2} \mu_{0} \varepsilon(r) E_{n}^{-}-\frac{2 n}{r^{2}} E_{n}^{-}=0
\end{aligned}
$$

and their general solutions can be written as Bessel functions expansion:

$$
\begin{aligned}
& E_{n}^{+}=\int_{k_{m}=0}^{\infty} 2 \tilde{c}_{n}^{E}\left(k_{m}, z\right) J_{n-1}\left(k_{m} r\right) k_{m} d k_{m} \\
& E_{n}^{-}=\int_{k_{m}=0}^{\infty} 2 \tilde{b}_{n}^{E}\left(k_{m}, z\right) J_{n+1}\left(k_{m} r\right) k_{m} d k_{m}
\end{aligned}
$$


with $\mathrm{k}_{\mathrm{m}}$ being the radial wavenumber $\mathrm{k}_{\mathrm{r}}$ of each Fourier-Bessel component. The usefulness of the substitution (29) and (30) can be further exploited. To this aim it is sufficient to add or subtract the first two equations in (26) , so that one obtains

$$
\begin{aligned}
& \frac{\partial \mathrm{E}_{\mathrm{n}}^{+}}{\partial \mathrm{z}}=\frac{\mathrm{in}}{\mathrm{r}} \mathrm{E}_{\mathrm{z}, \mathrm{n}}+\mathrm{i} \frac{\partial \mathrm{E}_{\mathrm{z}, \mathrm{n}}}{\partial \mathrm{r}}-\mathrm{i} \omega \mu_{0} \mathrm{H}_{\mathrm{n}}^{+} \\
& \frac{\partial \mathrm{E}_{\mathrm{n}}^{-}}{\partial \mathrm{z}}=\frac{\mathrm{in}}{\mathrm{r}} \mathrm{E}_{\mathrm{z}, \mathrm{n}}-\mathrm{i} \frac{\partial \mathrm{E}_{\mathrm{z}, \mathrm{n}}}{\partial \mathrm{r}}+\mathrm{i} \omega \mu_{0} \mathrm{H}_{\mathrm{n}}^{-}
\end{aligned}
$$

Projecting these equations on the basis of $\mathrm{J}_{\mathrm{n}-1}$ and $\mathrm{J}_{\mathrm{n}+1}$ results in first-order ordinary differential equations for $\tilde{b}_{n}^{E}$ and $\tilde{c}_{n}^{E}$. To this aim it is necessary to express $E_{z, n}$ in the same basis, which can be done from the last equation in (26). In the meantime, we have to take into account that the numerical calculations require truncating the basis of projection. This means that we have to replace the integrals by discrete sums bounded by a finite limit. In addition, the unknown functions $\tilde{b}_{n}^{E}\left(k_{m}, z\right)$ and $\tilde{c}_{n}^{E}\left(k_{m}, z\right)$ are turned into sets of discrete unknowns denoted by $b_{n, m}^{E}(z)=\tilde{b}_{n}^{E}\left(k_{m}, z\right) k_{m}$ and $c_{n, m}^{E}(z)=\tilde{c}_{n}^{E}\left(k_{m}, z\right) k_{m}$.

It is straightforward to find from the third and the sixth equation in (26) the expressions of z-components of $\mathrm{H}$ and $\mathrm{D}$ :

$$
\begin{aligned}
i \omega \mu_{0} H_{z, n} & =\sum_{m=1}^{M a x}\left(b_{n, m}^{E}-c_{n, m}^{E}\right) J_{n}\left(k_{m} r\right) k_{m} \Delta k_{m} \\
-i \omega D_{z, n} & =\sum_{m=1}^{M a x}\left(b_{n, m}^{H}-c_{n, m}^{H}\right) J_{n}\left(k_{m} r\right) k_{m} \Delta k_{m}
\end{aligned}
$$

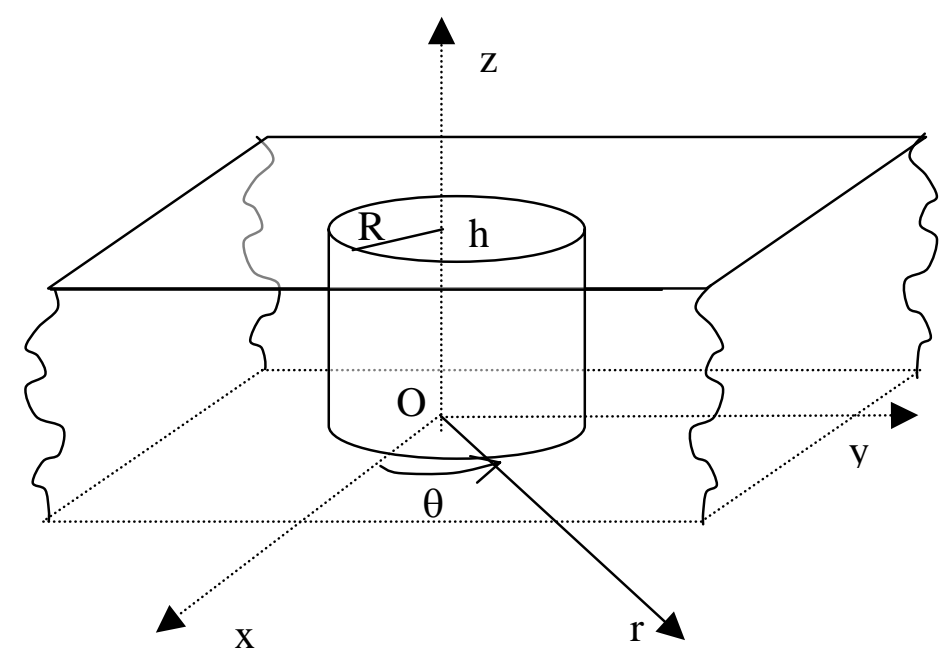

Fig.3 Schematical representation of a cylindrical aperture inside an infinite plane screen

The link between $E_{z, n}$ and $D_{z, n}$ depends on the system geometry. The factorizations rules discussed in the previous section depend on the form of the diffractive object. Let us consider the most simple system, which has a rotational symmetry and is piecewise z-independent. This could be a circular cylindrical aperture in a plane screen (Fig.3), or more complicated structure consisting of circular channels with rectangular cross section, as discussed further on. In principle, if the geometry varies with z, one can try to represent it in a staircase-like manner, as consisting of many discs having slightly changing radii. However, experience with diffraction gratings shows that this approximation cannot be applied to metallic objects, due to the strong edge effects appearing there [25].

Inside the aperture in Fig.3, the vector normal to its walls has only one component $\mathrm{N}_{\mathrm{r}}=1$ and eq.(24) simplifies considerably:

$$
\begin{gathered}
{\left[\mathrm{D}_{\mathrm{r}, \mathrm{n}}\right]^{\{\mathrm{n} \pm 1\}}=\left(\llbracket \frac{1}{\varepsilon} \rrbracket^{\{\mathrm{n} \pm 1\}}\right)^{-1}\left[\mathrm{E}_{\mathrm{r}, \mathrm{n}}\right]^{\{\mathrm{n} \pm 1\}}} \\
{\left[\mathrm{D}_{\theta, \mathrm{n}}\right]^{\{\mathrm{n} \pm 1\}}=\llbracket \varepsilon \rrbracket^{\{\mathrm{n} \pm 1\}}\left[\mathrm{E}_{\theta, \mathrm{n}}\right]^{\{\mathrm{n} \pm 1\}}}
\end{gathered}
$$


where

$$
\left[\mathrm{D}_{\mathrm{z}, \mathrm{n}}\right]^{\{\mathrm{n}\}}=\llbracket \varepsilon \rrbracket^{\{\mathrm{n}\}}\left[\mathrm{E}_{\mathrm{z}, \mathrm{n}}\right]^{\{\mathrm{n}\}}
$$

$$
\llbracket \varepsilon \rrbracket_{\mathrm{m}^{\prime}, \mathrm{m}}^{\{\mathrm{n}\}}=\mathrm{k}_{\mathrm{m}^{\prime}} \Delta_{\mathrm{m}} \int_{\mathrm{r}=0}^{\infty} \varepsilon(\mathrm{r}) \mathrm{J}_{\mathrm{n}}\left(\mathrm{k}_{\mathrm{m}}, \mathrm{r}\right) \mathrm{J}_{\mathrm{n}}\left(\mathrm{k}_{\mathrm{m}} \mathrm{r}\right) \mathrm{rdr}
$$

with $\Delta_{\mathrm{m}}=\mathrm{k}_{\mathrm{m}+1}-\mathrm{k}_{\mathrm{m}}$. The different choice of the upper index for the z-components can be understood comparing eqs.(33), (34) from one side, and (36) and (37), from the other.

As $E_{z, n}$ are continuous functions on the object walls and thus the factorization rule (40) applied to the lefthand side of eq.(37) must be the direct one, eq.(40), so that

$$
\mathrm{b}_{\mathrm{n}, \mathrm{m}^{\prime}}^{\mathrm{H}}-\mathrm{c}_{\mathrm{n}, \mathrm{m}^{\prime}}^{\mathrm{H}}=-\mathrm{i} \omega \sum_{\mathrm{m}=1}^{\mathrm{Max}} \llbracket \varepsilon \rrbracket_{\mathrm{m}^{\prime}, \mathrm{m}}^{\{\mathrm{n}\}}\left[\mathrm{E}_{\mathrm{z}, \mathrm{n}}\right]_{\mathrm{m}}^{\{\mathrm{n}\}}
$$

Equations (37) and (42) permit us to find Bessel-functions representation of $\mathrm{E}_{\mathrm{z}, \mathrm{n}}$ :

$$
\mathrm{E}_{\mathrm{z}, \mathrm{n}}=\frac{\mathrm{i}}{\omega} \sum_{\mathrm{m}=1}^{\mathrm{Max}} \mathrm{k}_{\mathrm{m}} \Delta \mathrm{k}_{\mathrm{m}} \mathrm{J}_{\mathrm{n}}\left(\mathrm{k}_{\mathrm{m}} \mathrm{r}\right) \sum_{\mathrm{m}^{\prime}=1}^{\mathrm{Max}}\left(\llbracket \varepsilon \rrbracket^{\{\mathrm{n}\}}\right)_{\mathrm{m}, \mathrm{m}^{\prime}}^{-1}\left[\mathrm{~b}_{\mathrm{n}, \mathrm{m}^{\prime}}^{\mathrm{H}}-\mathrm{c}_{\mathrm{n}, \mathrm{m}^{\prime}}^{\mathrm{H}}\right]
$$

Its substitution of eqs.(36) and (43) into eqs.(35) results in the following differential equations, after projecting the first one on $\mathrm{J}_{\mathrm{n}+1}$ and the second one on $\mathrm{J}_{\mathrm{n}-1}$ :

$$
\begin{aligned}
& \mathrm{b}_{\mathrm{n}, \mathrm{m}}^{\mathrm{E}}{ }^{\prime}=\omega \mu_{0} \mathrm{~b}_{\mathrm{n}, \mathrm{m}}^{\mathrm{H}}-\frac{\mathrm{k}_{\mathrm{m}}}{2 \omega} \sum_{\mathrm{m}^{\prime}=1}^{\mathrm{Max}}\left([\varepsilon]_{\tilde{\mathrm{m}}, \mathrm{m}^{\prime}}^{\{\mathrm{n}\}}\right)^{-1} \mathrm{k}_{\mathrm{m}^{\prime}}\left[\mathrm{b}_{\mathrm{n}, \mathrm{m}^{\prime}}^{\mathrm{H}}-\mathrm{c}_{\mathrm{n}, \mathrm{m}^{\prime}}^{\mathrm{H}}\right] \\
& \mathrm{c}_{\mathrm{n}, \mathrm{m}}^{\mathrm{E}{ }^{\prime}}=-\omega \mu_{0} \mathrm{c}_{\mathrm{n}, \mathrm{m}}^{\mathrm{H}}-\frac{\mathrm{k}_{\mathrm{m}}}{2 \omega} \sum_{\mathrm{m}^{\prime}=1}^{\mathrm{Max}}\left([\varepsilon]_{\tilde{\mathrm{m}}, \mathrm{m}^{\prime}}^{\{\mathrm{n}\}}\right)^{-1} \mathrm{k}_{\mathrm{m}^{\prime}}\left[\mathrm{b}_{\mathrm{n}, \mathrm{m}^{\prime}}^{\mathrm{H}}-\mathrm{c}_{\mathrm{n}, \mathrm{m}^{\prime}}^{\mathrm{H}}\right]
\end{aligned}
$$

where the prime stands for a derivative with respect to $\mathrm{z}$. In the homogeneous cladding and substrate, the field is represented as cylindrical waves and the $\mathrm{z}$-dependence of the field components is simply given by:

$$
\begin{aligned}
& \mathrm{b}_{\mathrm{n}, \mathrm{m}}(\mathrm{z}) \sim \exp \left( \pm \mathrm{i} \mathrm{k}_{\mathrm{z}, \mathrm{m}} \mathrm{z}\right) \\
& \mathrm{k}_{\mathrm{z}, \mathrm{m}}=\sqrt{\mathrm{k}_{0}^{2} \varepsilon-\mathrm{k}_{\mathrm{m}}^{2}}
\end{aligned}
$$

Inside the inhomogeneous region $(0<\mathrm{z}<\mathrm{h})$, it is necessary to make numerical integration.

The remaining couple of differential equations for $b_{n, m}^{H}$ and $c_{n, m}^{H}$ can be found by adding and subsracting the fourth and the fifth equations in (26):

$$
\begin{aligned}
& \frac{\partial \mathrm{H}_{\mathrm{n}}^{+}}{\partial \mathrm{z}}=\frac{\mathrm{in}}{\mathrm{r}} \mathrm{H}_{\mathrm{z}, \mathrm{n}}+\mathrm{i} \frac{\partial \mathrm{H}_{\mathrm{z}, \mathrm{n}}}{\partial \mathrm{r}}+\mathrm{i} \omega\left(\mathrm{D}_{\theta, \mathrm{n}}+\mathrm{iD}_{\mathrm{r}, \mathrm{n}}\right) \\
& \frac{\partial \mathrm{H}_{\mathrm{n}}^{-}}{\partial \mathrm{z}}=\frac{\mathrm{in}}{\mathrm{r}} \mathrm{H}_{\mathrm{z,n}}-\mathrm{i} \frac{\partial \mathrm{H}_{\mathrm{z}, \mathrm{n}}}{\partial \mathrm{r}}-\mathrm{i} \omega\left(\mathrm{D}_{\theta, \mathrm{n}}-\mathrm{iD}_{\mathrm{r}, \mathrm{n}}\right)
\end{aligned}
$$

The complication comes from the necessity to apply simultaneously the direct and the inverse rules. By using eqs.(29) and (30), we obtain:

$$
\begin{aligned}
& E_{r}(r, z)=i \sum_{n=-N}^{N} \sum_{m=1}^{M a x} \Delta k_{m}\left[b_{n, m}^{E}(z) J_{n+1}\left(k_{m} r\right)-c_{n, m}^{E}(z) J_{n-1}\left(k_{m} r\right)\right] \exp (i n \theta) \\
& E_{\theta}(r, z)=\sum_{n=-N}^{N} \sum_{m=1}^{M a x} \Delta k_{m}\left[b_{n, m}^{E}(z) J_{n+1}\left(k_{m} r\right)+c_{n, m}^{E}(z) J_{n-1}\left(k_{m} r\right)\right] \exp (i n \theta)
\end{aligned}
$$

and similar presentation for the magnetic field. These equations show that the field components are naturally expanded in a mixed basis containing both $\mathrm{J}_{\mathrm{n}-1}$ and $\mathrm{J}_{\mathrm{n}+1}$. One can pass from one to another by using simples integrals that can easily be evaluated analytically: 


$$
\mathbb{I}_{\mathrm{m}, \mathrm{m}^{\prime}}^{\{+,-\}}=\mathrm{k}_{\mathrm{m}} \Delta_{\mathrm{m}^{\prime}} \int_{0}^{\infty} \mathrm{J}_{\mathrm{n}+1}\left(\mathrm{k}_{\mathrm{m}} \mathrm{r}\right) \mathrm{J}_{\mathrm{n}-1}\left(\mathrm{k}_{\mathrm{m}^{\prime}} \mathrm{r}\right) \mathrm{r} \mathrm{dr}
$$

so that two different representation can be used:

$$
\begin{aligned}
& {\left[\mathrm{E}_{\mathrm{r}, \mathrm{n}}\right]_{\mathrm{m}}^{\{\mathrm{n}+1\}}=\mathrm{ib} \mathrm{n}_{\mathrm{m}, \mathrm{m}}^{\mathrm{E}}(\mathrm{z})-\mathrm{i} \sum_{\mathrm{m}^{\prime}=0}^{\mathrm{Max}} \mathbb{I}_{\mathrm{m}, \mathrm{m}^{\prime}}^{\{+,-} \mathrm{c}_{\mathrm{n}, \mathrm{m}^{\prime}}^{\mathrm{E}}(\mathrm{z})} \\
& {\left[\mathrm{E}_{\mathrm{r}, \mathrm{n}}\right]_{\mathrm{m}}^{\{\mathrm{n}-1\}}=\mathrm{i} \sum_{\mathrm{m}^{\prime}=0}^{\mathrm{Max}} \mathbb{I}_{\mathrm{m}, \mathrm{m}^{\prime}}^{\{-,+} \mathrm{b}_{\mathrm{n}, \mathrm{m}^{\prime}}^{\mathrm{E}}(\mathrm{z})-\mathrm{ic}_{\mathrm{n}, \mathrm{m}}^{\mathrm{E}}(\mathrm{z})}
\end{aligned}
$$

and similar expressions apply for $E_{\theta}, H_{r}$, and $H_{\theta}$. These expression can be used in eqs.(38) and (39). Then, the first of eqs.(46) is projected onto $J_{n-1}$ basis, and the second one, onto $J_{n+1}$ basis. As a result, the second couple is born [26]:

$$
\begin{aligned}
& b_{n, m}^{H}{ }^{H}=\frac{k_{m}^{2}}{2 \omega \mu_{0}}\left(b_{n, m}^{E}-c_{n, m}^{E}\right) \\
& \left.-\frac{\omega}{2} \sum_{\mathrm{m}^{\prime}}\left\{\left(\llbracket \varepsilon \rrbracket^{\{\mathrm{n}+1\}}+\llbracket \frac{1}{\varepsilon} \rrbracket^{\{\mathrm{n}+1\}^{-1}}\right)_{\mathrm{m}, \mathrm{m}^{\prime}} \mathrm{b}_{\mathrm{n}, \mathrm{m}^{\prime}}^{\mathrm{E}}+\left[\llbracket \llbracket \rrbracket^{\{\mathrm{n}+1\}}-\llbracket \frac{1}{\varepsilon} \rrbracket^{\{\mathrm{n}+1\}^{-1}}\right) \mathbb{I}^{\{+,-\}}\right]_{\mathrm{m}, \mathrm{m}^{\prime}} \mathrm{c}_{\mathrm{n}, \mathrm{m}^{\prime}}^{\mathrm{E}}\right\} \\
& \mathrm{c}_{\mathrm{n}, \mathrm{m}}^{\mathrm{H}}{ }^{\prime}=\frac{\mathrm{k}_{\mathrm{m}}^{2}}{2 \omega \mu_{0}}\left(\mathrm{~b}_{\mathrm{n}, \mathrm{m}}^{\mathrm{E}}-\mathrm{c}_{\mathrm{n}, \mathrm{m}}^{\mathrm{E}}\right) \\
& +\frac{\omega}{2} \sum_{\mathrm{m}^{\prime}}\left\{\left[\llbracket \varepsilon \rrbracket^{\{\mathrm{n}-1\}}-\llbracket \frac{1}{\varepsilon} \rrbracket^{\{\mathrm{n}-1\}^{-1}} \rrbracket^{\{-,+\}}\right]_{\mathrm{m}, \mathrm{m}^{\prime}} \mathrm{b}_{\mathrm{n}, \mathrm{m}^{\prime}}^{\mathrm{E}}+\left(\llbracket \varepsilon \rrbracket^{\{\mathrm{n}-1\}}+\llbracket \llbracket \frac{1}{\varepsilon} \rrbracket^{\{\mathrm{n}-1\}^{-1}}\right)_{\mathrm{m}, \mathrm{m}^{\prime}} \mathrm{c}_{\mathrm{n}, \mathrm{m}^{\prime}}^{\mathrm{E}}\right\}
\end{aligned}
$$

\section{Solution of the diffraction problem}

From to the continuity of the $\mathrm{r}$ - and $\theta$-components of the electric and magnetic field vectors on the inhomogeneous medium boundaries at $\mathrm{z}=0$ and h, it follows that the Fourier-Bessel amplitudes $b_{n, m}^{E, H}, c_{n, m}^{E, H}$ are continuous functions of $z$ everywhere in space. As already found in eq.(45), they have analytical form in the outermost homogeneous media. Let us construct a column vector $\mathrm{F}(\mathrm{z})$ containing as subelements the column vectors $\left[b_{n}^{E, H}\right],\left[c_{n}^{E, H}\right]$ having, respectively, elements $b_{n, m}^{E, H}, c_{n, m}^{E, H}$ :

$$
\mathrm{F}_{\mathrm{n}}(\mathrm{z})=\left(\begin{array}{l}
{\left[\mathrm{b}_{\mathrm{n}}^{\mathrm{E}}\right]} \\
{\left[\mathrm{c}_{\mathrm{n}}^{\mathrm{E}}\right]} \\
{\left[\mathrm{b}_{\mathrm{n}}^{\mathrm{H}}\right]} \\
{\left[\mathrm{c}_{\mathrm{n}}^{\mathrm{H}}\right]}
\end{array}\right)
$$

Then the differential system of equations in (44) and (52) can be written in a matrix form:

$$
\mathrm{F}_{\mathrm{n}}^{\prime}=\mathrm{M}_{\mathrm{n}} \mathrm{F}_{\mathrm{n}}
$$

where the diffraction matrix $M_{n}$ has elements given in the right-hand side of eqs.(44) and (52). If, as assumed before, the diffractive system has a rotational geometry, the set of field components for a given value of $n$ (the number of Fourier component with respect to $\theta$ ) is completely independent from the sets having other values of $\mathrm{n}$. Thus, if the number of Fourier components in $\theta$ is truncated to $-\mathrm{N}_{\max } \leq \mathrm{n} \leq \mathrm{N}_{\max }$ and the number of discrete values of $\mathrm{k}_{\mathrm{m}}$ is limited to $\mathrm{M}_{\max }$, the differential system and the boundary conditions between the homogeneous and inhomogeneous media requires solving independently $2 \mathrm{~N}_{\max }+1$ times the system (53) of 
$4 \mathrm{M}_{\max }$ equations, a problem much easier than if the equations were coupled in $\mathrm{n}$, as they are coupled in $\mathrm{m}$, which should have led to a system of $4 \mathrm{M}_{\max } \mathrm{x}\left(2 \mathrm{~N}_{\max }+1\right)$ coupled equations.

In the case of piecewisely $\mathrm{z}$-independent geometry, in each region invariant in $\mathrm{z}$, the M-matrix is $\mathrm{z}$ independent and another simplification is welcome, the same as in the RCW method [11 - 14]. Then, is possible to solve eq.(54) using eigenvalue/eigenvector technique, in a matter similar to the rigorous coupled-wave method for lamellar gratings. If $\left\{\rho_{m}\right\}$ is the set of eigenvalues of $M_{n}$, and matrix $V$ contains as columns the corresponding eigenvectors, the solution of eq.(54) can be explicitly represented in a matrix form and it is proportional to $4 \mathrm{M}_{\max }$ unknown constants, representing the values of $\mathrm{F}_{\mathrm{n}}$ at, say, $\mathrm{z}=0$ :

$$
\mathrm{F}_{\mathrm{n}}(\mathrm{z})=\mathrm{V} \Phi(\mathrm{z}) \mathrm{V}^{-1} \mathrm{~F}_{\mathrm{n}}(0)
$$

where $\Phi(\mathrm{z})$ is a diagonal matrix with elements

$$
\Phi_{\mathrm{mp}}(\mathrm{z})=\delta_{\mathrm{mp}} \exp \left(\rho_{\mathrm{m}} \mathrm{z}\right)
$$

$\delta_{\mathrm{mp}}$ being the Kroneker symbol. In the cladding, the cylindrical waves can be separated into two parts, $2 \mathrm{M}_{\max }$ incident components with known amplitudes and having $\mathrm{z}$-dependence $\exp \left(-\mathrm{i} \mathrm{k}_{\mathrm{z} \text {,cladding }} \mathrm{z}\right)$, and $2 \mathrm{M}_{\max }$ unknown reflected components, proportional to $\exp \left(\mathrm{ik}_{\mathrm{z} \text {,cladding }} \mathrm{z}\right)$. If there is no incidence from the substrate, there are only $2 \mathrm{M}_{\text {max }}$ transmitted waves propagating downwards $\sim \exp \left(-\mathrm{ik}_{\mathrm{z} \text {,substrate }} \mathrm{z}\right)$

Boundary conditions at $\mathrm{z}=0$ and $\mathrm{z}=\mathrm{h}$ lead to $8 \mathrm{M}_{\max }$ equations for the same number of unknown amplitudes ( $2 \mathrm{M}_{\max }$ in the cladding, $2 \mathrm{M}_{\max }$ in the substrate and $4 \mathrm{M}_{\max }$ in the inhomogeneous layer):

$$
\begin{aligned}
& \mathrm{F}_{\text {clad. }} \equiv \mathrm{F}^{-}(\mathrm{h})+\mathrm{F}^{+}(\mathrm{h})=\mathrm{V} \Phi(\mathrm{h}) \mathrm{V}^{-1} \mathrm{~F}_{\mathrm{n}}(0) \\
& \mathrm{F}_{\text {transmitted }}=\mathrm{F}_{\mathrm{n}}^{-}(0)
\end{aligned}
$$

Signs minus and plus stand for down- and upgoing waves, respectively. Thus $\mathrm{F}^{-}(\mathrm{h})$ corresponds to the known incident waves. Solving this linear system for different values of $\mathrm{n}$ and for a given incident wave, presented in the same basis, makes it possible to determine the electric field components using eqs.(47) and (48). Similar equations hold for the magnetic field.

\section{Some precautions}

Although the procedure described in the previous section is straightforward, it contains several traps. First, working in the k-space always need playing special attention to the singularities (poles, corresponding to surface or guided waves or other resonances, and branching points). To better describe them, it is possible to refine the discretization of $\mathrm{k}_{\mathrm{m}}$ close to the singularities or, better, to go around them in the complex k-plane.

Second, as for lamellar gratings, it is possible to demonstrate theoretically that the form of the matrix $M_{n}$ requires that its eigenvalues appear in couples $\pm \rho_{\mathrm{m}}$, and thus the eigenvalues having large negative imaginary parts can create numerical problems, when the thickness $h$ is sufficiently large, as described in section 2 . One of the possibilities to overcome this difficulty is to use the S-matrix algorithm by cutting the entire integration distance in slices. The second possibility is to use the special symmetry of the matrices V and F, in a manner similar to the RCW method [27]. The fact that the eigenvalues appear in couples permit us to 'quarantine' those of them that lead to numerical instabilities, namely the ones having negative imaginary part. Let us separate them in two groups:

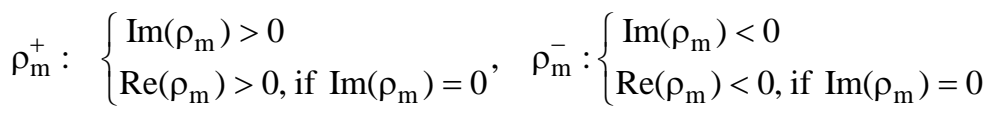

The eigenvector matrix and ist inverse can be divided into 4 blocks each:

$$
\mathrm{V}=\left(\begin{array}{ll}
\mathrm{V}_{11} & \mathrm{~V}_{12} \\
\mathrm{~V}_{21} & \mathrm{~V}_{22}
\end{array}\right), \quad \mathrm{V}^{-1}=\left(\begin{array}{ll}
\mathrm{W}_{11} & \mathrm{~W}_{12} \\
\mathrm{~W}_{21} & \mathrm{~W}_{22}
\end{array}\right)
$$


in a manner that the first block-column of $\mathrm{V}$ corresponds to $\left\{\rho_{\mathrm{m}}^{+}\right\}$. Equation (55) can then be rewritten in the following block form:

$$
F(z)=\left(\begin{array}{cc}
V_{11} & V_{12} \\
V_{21} & V_{22}
\end{array}\right)\left(\begin{array}{cc}
\exp \left(\rho_{m}^{+} z\right) & 0 \\
0 & \exp \left(\rho_{m}^{-} z\right)
\end{array}\right)\left(\begin{array}{ll}
W_{11} & W_{12} \\
W_{21} & W_{22}
\end{array}\right)\left(\begin{array}{l}
F^{+}(0) \\
F^{-}(0)
\end{array}\right)
$$

where the 'substrate' vector is divided into upgoing $\mathrm{F}^{+}$and downgoing $\mathrm{F}^{-}$parts. Without incidence from the substrate, $\mathrm{F}^{+}=0$, thus

$$
\begin{aligned}
F(z) & =\left(\begin{array}{cc}
V_{11} & V_{12} \\
V_{21} & V_{22}
\end{array}\right)\left(\begin{array}{cc}
\exp \left(\rho_{\mathrm{m}}^{+} \mathrm{z}\right) & 0 \\
0 & \exp \left(\rho_{\mathrm{m}^{\prime}}^{-} \mathrm{z}\right)
\end{array}\right)\left(\begin{array}{c}
\mathrm{W}_{12} \\
\mathrm{~W}_{22}
\end{array}\right) \mathrm{F}^{-}(0) \\
& =\left(\begin{array}{cc}
\mathrm{V}_{11} & \mathrm{~V}_{12} \\
\mathrm{~V}_{21} & \mathrm{~V}_{22}
\end{array}\right)\left(\begin{array}{c}
\exp \left(\rho_{\mathrm{m}}^{+} \mathrm{z}\right) \mathrm{W}_{12} \\
\exp \left(\rho_{\mathrm{m}^{\prime}}^{-} \mathrm{z}\right) \mathrm{W}_{22}
\end{array}\right) \mathrm{F}^{-}(0) \\
& =\left(\begin{array}{cc}
\mathrm{V}_{11} & \mathrm{~V}_{12} \\
\mathrm{~V}_{21} & \mathrm{~V}_{22}
\end{array}\right)\left(\begin{array}{c}
\exp \left(\rho_{\mathrm{m}}^{+} \mathrm{z}\right) \mathrm{W}_{12} \mathrm{~W}_{22}^{-1} \exp \left(-\rho_{\mathrm{m}^{\prime}}^{-} \mathrm{z}\right) \\
\mathrm{I}
\end{array}\right) \exp \left(\rho_{\mathrm{m}^{\prime}}^{-} \mathrm{z}\right) \mathrm{W}_{22} \mathrm{~F}^{-}(0) \\
& =\left(\begin{array}{cc}
\mathrm{V}_{11} & \mathrm{~V}_{12} \\
\mathrm{~V}_{21} & \mathrm{~V}_{22}
\end{array}\right)\left(\begin{array}{c}
\exp \left(\rho_{\mathrm{m}}^{+} \mathrm{z}\right) \mathrm{W}_{12} \mathrm{~W}_{22}^{-1} \exp \left(-\rho_{\mathrm{m}^{\prime}}^{-} \mathrm{z}\right) \\
\mathrm{I}
\end{array}\right) \hat{\mathrm{F}}^{-}(0)
\end{aligned}
$$

with a renormalization $\hat{\mathrm{F}}^{-}(0)=\exp \left(\rho_{\mathrm{m}^{\prime}}^{-} \mathrm{z}\right) \mathrm{W}_{22} \mathrm{~F}^{-}(0)$ of the transmitted field amplitudes. The advantage of the last term in eq.(61) is that it does not contains any growing exponentials and causes no numerical problem, whatever the screen thickness is.

Third problem appears during the field reconstruction made by using eqs.(47) and (48). Replacing the integrals in eqs.(33) and (34) by discrete sums introduces spurious quasiperiodicity (phantom scatteres), periodicity inversely proportional to the mean discretization step of $\mathrm{k}_{\mathrm{m}}$. For large values of the product $\mathrm{k}_{\mathrm{m}} \mathrm{r}$, the Bessel functions in (33) and (34) vary more rapidly than the field coefficients $b_{n, m}^{E}$ and $c_{n, m}^{E}$, so that the integral in (34) cannot be represented as a simple sum in $\mathrm{m}$ of terms:

$$
\mathrm{b}_{\mathrm{n}, \mathrm{m}}^{\mathrm{E}} \Delta \mathrm{k}_{\mathrm{m}} \mathrm{J}_{\mathrm{n}+1}\left(\mathrm{k}_{\mathrm{m}} \mathrm{r}\right)
$$

In that case it is more appropriate to replace the integral by a sum of more complicated terms:

$$
b_{n, m}^{E} \int_{k_{m-1}}^{k_{m}} J_{n+1}\left(k_{r} r\right) d k_{r}
$$

These integrals can be evaluated analytically by using the asymptotic expansion of the Bessel functions for large arguments [28].

The forth remarks concerns the evaluation of the matrix coefficients of $\varepsilon$, eq.(41). This can be done analytically for a single aperture or for an aperture surrounded by circular channels having vertical walls, so that $\varepsilon$ is a piecewise constant function of $\mathrm{r}$. Let us demonstrate this for a single circular aperture having radius R:

$$
\begin{aligned}
& \llbracket \varepsilon \rrbracket_{\mathrm{m}^{\prime}, \mathrm{m}}^{\{\mathrm{n}\}}=\mathrm{k}_{\mathrm{m}^{\prime}} \Delta_{\mathrm{m}} \int_{\mathrm{r}=0}^{\infty} \varepsilon(\mathrm{r}) \mathrm{J}_{\mathrm{n}}\left(\mathrm{k}_{\mathrm{m}}, \mathrm{r}\right) \mathrm{J}_{\mathrm{n}}\left(\mathrm{k}_{\mathrm{m}} \mathrm{r}\right) \mathrm{rdr} \\
& =\mathrm{k}_{\mathrm{m}^{\prime}} \Delta_{\mathrm{m}} \int_{0}^{\mathrm{R}} \varepsilon_{\mathrm{a}} \mathrm{J}_{\mathrm{n}}\left(\mathrm{k}_{\mathrm{m}}, \mathrm{r}\right) \mathrm{J}_{\mathrm{n}}\left(\mathrm{k}_{\mathrm{m}} \mathrm{r}\right) \mathrm{rdr}+\mathrm{k}_{\mathrm{m}^{\prime}} \Delta_{\mathrm{m}} \int_{\mathrm{R}}^{\infty} \varepsilon_{\mathrm{b}} \mathrm{J}_{\mathrm{n}}\left(\mathrm{k}_{\mathrm{m}}, \mathrm{r}\right) \mathrm{J}_{\mathrm{n}}\left(\mathrm{k}_{\mathrm{m}} \mathrm{r}\right) \mathrm{rdr} \\
& =\mathrm{k}_{\mathrm{m}^{\prime}} \Delta_{\mathrm{m}} \int_{0}^{\infty} \varepsilon_{\mathrm{a}} \mathrm{J}_{\mathrm{n}}\left(\mathrm{k}_{\mathrm{m}}, \mathrm{r}\right) \mathrm{J}_{\mathrm{n}}\left(\mathrm{k}_{\mathrm{m}} \mathrm{r}\right) \mathrm{rdr}+\mathrm{k}_{\mathrm{m}^{\prime}} \Delta_{\mathrm{m}}\left(\varepsilon_{\mathrm{b}}-\varepsilon_{\mathrm{a}}\right) \int_{0}^{\mathrm{R}} \mathrm{J}_{\mathrm{n}}\left(\mathrm{k}_{\mathrm{m}}, \mathrm{r}\right) \mathrm{J}_{\mathrm{n}}\left(\mathrm{k}_{\mathrm{m}} \mathrm{r}\right) \mathrm{rdr} \\
& =\varepsilon_{\mathrm{a}} \Delta_{\mathrm{m}}+\mathrm{Rk}_{\mathrm{m}^{\prime}} \Delta_{\mathrm{m}} \frac{\left(\varepsilon_{\mathrm{b}}-\varepsilon_{\mathrm{a}}\right)}{\mathrm{k}_{\mathrm{m}^{\prime}}^{2}-\mathrm{k}_{\mathrm{m}}^{2}}\left[\mathrm{~J}_{\mathrm{n}+1}\left(\mathrm{k}_{\mathrm{m}}, \mathrm{R}\right) \mathrm{J}_{\mathrm{n}}\left(\mathrm{k}_{\mathrm{m}} \mathrm{R}\right)-\mathrm{J}_{\mathrm{n}}\left(\mathrm{k}_{\mathrm{m}}, \mathrm{R}\right) \mathrm{J}_{\mathrm{n}+1}\left(\mathrm{k}_{\mathrm{m}} \mathrm{R}\right)\right]
\end{aligned}
$$




\section{Two numerical examples}

The first example concerns the near-field distribution after a circular aperture in a thick metallic screen. The electric field map is shown in Fig.4 and several interesting features can be observed. First, the field distribution is anisotropic, with two sharp peaks appearing close to the aperture edges in direction of the incident wave polarization. They are due to the edge effects of accumulation of charges due to the surface current discontinuity on the edges.

The second feature is the more rapid decrease of the field intensity when going away from the aperture in the $\mathrm{y}$-direction perpendicular to the incident polarization, when compared to the $\mathrm{x}$-direction parallel to the incident polarization, a feature better viewed in Fig.5 on the map of the z-component of the electric field vector calculated at a distance of $15 \mathrm{~nm}$ after the aperture. This asymetry is due to the excitation of surface plasmonpolariton wave, propagating in $\mathrm{x}$-direction, its amplitude decreasing as [29]:

$$
\mathrm{H}_{1}^{+}\left(\mathrm{k}_{\mathrm{p}} \mathrm{r}\right) \cos (\theta) \underset{\mathrm{r} \rightarrow \infty}{\longrightarrow} \frac{1}{\sqrt{\mathrm{k}_{\mathrm{p}}^{\prime} \mathrm{r}}} \exp \left(-\mathrm{k}_{\mathrm{p}}^{\prime \prime} \mathrm{r}\right) \cos (\theta)
$$

where $k_{p} \equiv k_{p}^{\prime}+i k_{p}^{\prime \prime}$ is the surface wave propagation constant. As determined by the symmetry of the incident wave polarized along the $x$-axis, in azimuthal direction its field behaves as $\cos (\theta)$ [29] and thus the plasmon contribytion to the total diffracted field vanishes along the $\mathrm{y}$-axis and is maximal along the $\mathrm{x}$-axis, which explains the more rapid decrease of the total radiated field in y-direction.

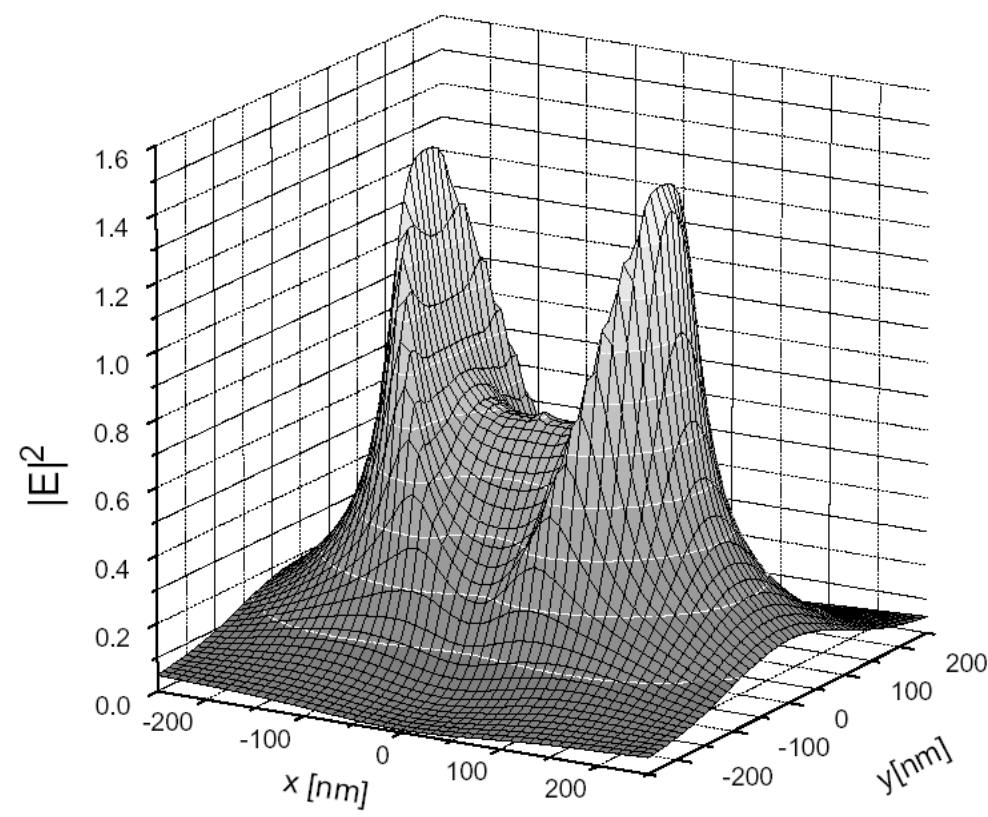

Fig.4 Modulus square of electric field transmitted through a circular aperture $(\mathrm{R}=125 \mathrm{~nm})$ pierced in a 200 $\mathrm{nm}$ thick silver screen. Wavelength $\lambda=500 \mathrm{~nm}$, normal incidence with incident polarization along the $\mathrm{x}$-axis. The field map is taken at $15 \mathrm{~nm}$ after the screen $(\mathrm{z}=-15 \mathrm{~nm})$. 


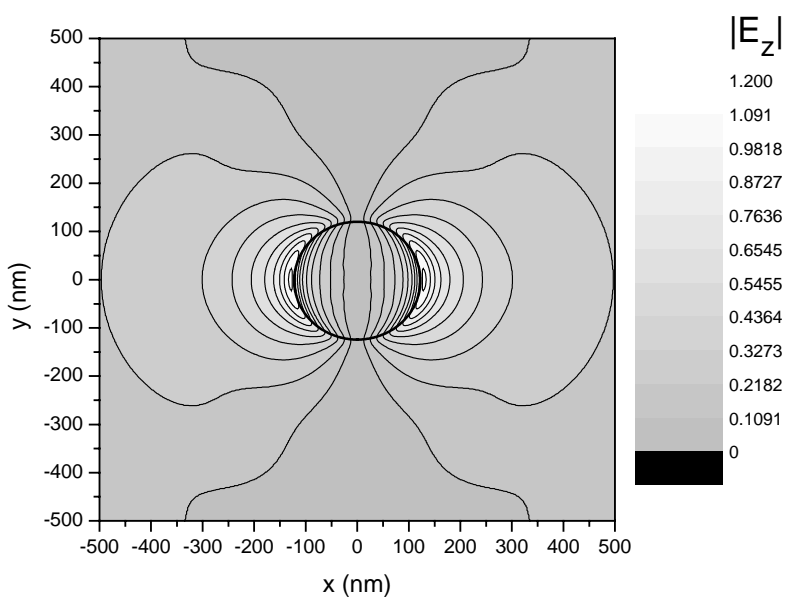

Fig.5 Same as in Fig.4, but for the map of the modulus of the z-component of electric field

As an illustration to eq.(65), Fig.6 presents a comparison between the x-dependence of $\left|E_{z}\right|$, given by eq.(65) and calculated by the rigorous differential method, presented above. As one can observe, almost the entire intensity along the surface in $\mathrm{x}$-direction is carried by the cylindrical plasmon surface wave

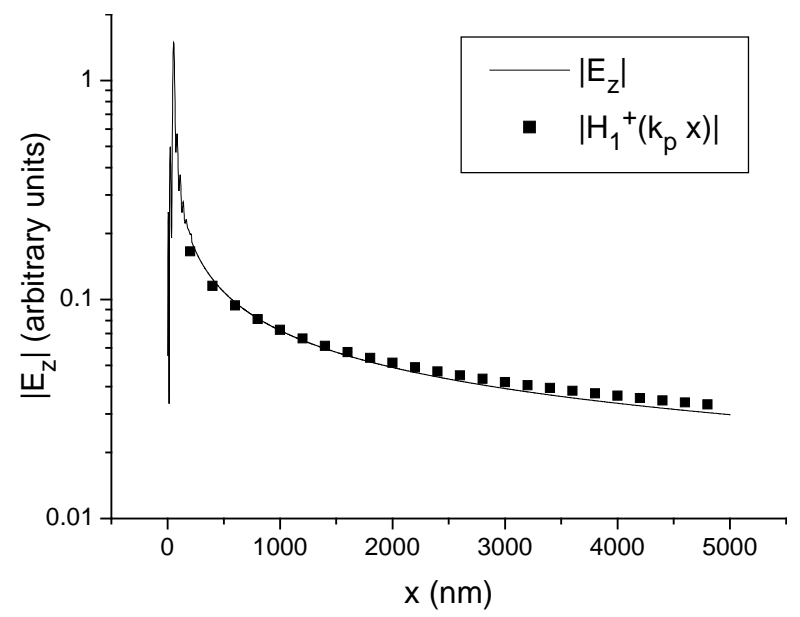

Fig.6 $\left|E_{z}\right|$ as a function of $x$ along the surface of a silver screen pierced by a $50 \mathrm{~nm}$ radius aperture.

Wavelength $500 \mathrm{~nm}$, incident polarization along the $\mathrm{x}$-axis. Full line, rigorous results, squares, eq. (65)

The second example concerns the far-field radiation pattern, as shown in Fig.7 for different screen materials. When the aperture is much smaller than the wavelength, one can expect that its radiation pattern is independent of the polar angle in a plane Oxz containing the incident electric field vector [30,31], while strongly varying in the perpendicular plane Oyz. These two features can be observed in Fig.7 for perfectly conducting screen. However, when the conductivity decreases, the radiation pattern in the Oxz plane becomes more directive [32].

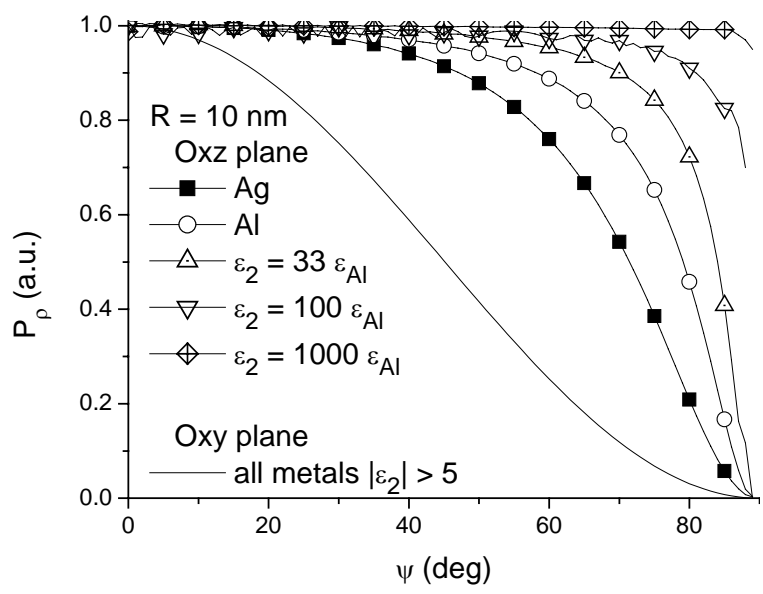


Fig.7 Polar angular distribution of the field flux diffracted by a circular aperture $(\mathrm{R}=10 \mathrm{~nm})$ for different screen materials with increasing conductivity. Wavelength $\lambda=500 \mathrm{~nm}$, normal incidence with polarization along the $\mathrm{x}$-axis. The polar angle $\psi$ is measured from the $\mathrm{z}$-axis.

\section{Conclusion}

The differential method of light diffraction that has found numerous applications in grating studies [1-7, 9-15], waveguide optics, Raman scattering [33], is successfully applied in cylindrical geometry to the study of diffraction by circular apertures in perfectly or finitely conducting screens, which permitted determining the role of the surface plasmon in the near-field distribution and the importance of the finite conductivity in increasing the directivity of the far-field radiation pattern. The method can successfully compete with other known methods working in Cartesian coordinates, like the adaptive-mesh FDTD [34] or the Fourier-series method with perfectmatching layers (PML) [35].

\section{References}

[1] Electromagnetic Theory of Gratings, ed. R. Petit (Springer-Verlag, Berlin, 1980)

[2] M. Nevière and E. Popov: Light Propagation in Periodic Media: Diffraction Theory and Design, (Marcel Dekker, New York, 2003).

[3] E. Popov and M. Neviere, J. Opt. Soc. Am. A 17, 1773-1784 (2000)

[4] L.C. Botten, M.S. Craig, R.C. McPhedran, J.L. Adams, and J.R. Andrewartha, Opt. Acta 28, 413 (1981)

[5] B. Gralak, M. de Dood, G. Tayeb, S. Enoch, and D. Maystre, Phys. Rev. E 67, 066601 (2003)

[6] M. Nevière, M. Cadilhac, and R. Petit, IEEE Trans. Ant. Propag. AP-21, 37-46 (1973)

[7] M. Nevière, R. Petit, and M. Cadilhac, Opt. Commun. 8, 113-117 (1973)

[8] M. A. Melkanoff, T. Sawada, and J. Raynal, in Methods in Computational Physics, 1-80, (Academic Press, New York, 1966)

[9] M. Nevière, P. Vincent, R. Petit, and M. Cadilhac, Opt. Commun. 9, 48-53 (1973)

[10] M. Nevière, P. Vincent, and R. Petit, Nouv. Rev. Opt. 5, 65-77 (1974)

[11] M. G. Moharam and T. K. Gaylord, J. Opt. Soc. Am. 71, 811-818 (1981)

[12] M. G. Moharam and T. K. Gaylord, J. Opt. Soc. Am. 72, 1385-1392 [1982)

[13] S. T. Peng, T. Tamir, and H. L. Bertoni, IEEE Trans. Microwave Theory and Techn. MTT-23, 123-133 (1975)

[14] E. I. Krupitsky and B. C. Chernov, (in Russian), Proc. IX All-Union School of Holography, Leningrad, 1977, pp. 84-95 (1977)

[15] L. Li, J. Opt. Soc. Am. A 13, 1024-1035 (1996)

[16] D. J. Zvijac and J. C. Light, Chem. Phys. 12, 237-251 (1976)

[17] J. C. Light and B. Walker, J. Chem. Phys. 65, 4272-4282 (1976)

[18] P. Lalanne and G. M. Morris, J. Opt. Soc. Am. A 13, 779-784 (1996)

[19] G. Granet and B. Guizal, J. Opt. Soc. Am. A 13, 1019-1023 (1996)

[20] L. Li, J. Opt. Soc. Am. A 13, 1870-1876 (1996)

[21] L. Li, in Mathematical Modeling in Optical Science, Frontiers in Applied Mathematics, eds. G. Bao, L. Cowsar and W. Masters, pp. 111-139, (Soc. Industr. and Appl. Math., Philadelphia, 2001)

[22] C. Sauvan, P. Lalanne, and J.P. Hugonin, Opt. Quant. Electron. 36, 271-284 (2004)

[23] E. Popov, M. Nevière, and N. Bonod, J. Opt. Soc. Am. A, 21, 46-51 (2004)

[24] N. Bonod, E. Popov, and M. Neviere, Opt. Commun. 244, 389-398 (2005)

[25] E.Popov, M.Nevière, B. Gralak, and G. Tayeb, J. Opt. Soc. Am. A. 19, $33-42$ (2002)

[26] N. Bonod, E. Popov, and M. Neviere, J. Opt. Soc. Am. A 22, 481-490 (2005)

[27] M.G. Moharam, E.B. Grann, D.A. Pommet and T.K. Gaylord, J. Opt. Soc. Am. A 12, 1068-1076 (1995)

[28] M. Abramovitz and I. A. Stegun, (eds.) Handbook of Mathematical Functions [9th printing (1970)] National Bureau of Standards Applied Mathematics Series 55. US Gov't Printing Office, Washington, DC (1964)

[29] E. Popov, M. Nevière, A.-L. Fehrembach, and N. Bonod, Appl. Opt. 44, 6141-6154 (2005)

[30] H. A. Bethe, Phys. Rev. 66, 163-182 (1944)

[31] J. D. Jackson, Classical Electrodynamics, $3^{\text {rd }}$ ed. (John Wiley, New York, 1998)

[32] E. Popov, M. Nevière, A. Sentennac, N. Bonod, A.-L. Ferrenbach, J. Wenger, P.-F. Lenne, and H. Rigneault, J. Opt. Soc. Am. A 24, 339-358 (2007)

[33] I. Savatinova, S. Tonchev, E. Popov, E. Liarokapis, and S. Raptis, J. Phys. D 25, 106-112 (1992)

[34] R. Zakharian, M. Mansuripur, and J. V. Moloney, Opt. Express 12, 2631-2648 (2004)

[35] E. Silberstein, P. Lalanne, J.P. Hugonin and Q. Cao, J. Opt. Soc. Am. A. 18, 2865-75 (2001) 